\title{
Caracterização morfométrica de folíolos de Moringa oleifera por método
} destrutivo

\author{
Ana Paula Silva Macário ${ }^{1}$, Diego de Albuquerque Coêlho ${ }^{1}$, Eliane Nunes da Silva ${ }^{2}$, Patrícia da Silva Costa ${ }^{1}$, Rener \\ Luciano de Souza Ferraz ${ }^{2}$ José Félix de Brito Neto ${ }^{2}$,
}

${ }^{1}$ Universidade Federal de Campina Grande, apaula.macario@gmail.com; diegoalbuqerqec@gmail.com; patriciagroambiental@gmail.com; ${ }^{2}$ Universidade Estadual da Paraíba, lianbela2010@gmail.com; ferragroestat@gmail.com; netobrito@bol.com.br.

\begin{abstract}
RESUMO: O objetivo deste estudo foi caracterizar morfométricamente folíolos de mudas de $M$. oleifera por método destrutivo. A pesquisa foi realizada no Centro de Ciências Agrárias e Ambientais da Universidade Estadual da Paraíba. Foram coletados 200 folíolos de $M$. oleifera, nos quais foram realizadas medidas para determinação do comprimento (C) e da largura (L) e, posteriormente, a área foliar foi determinada utilizando-se do softwareImage ${ }^{\circledR}$. Verificou-se que

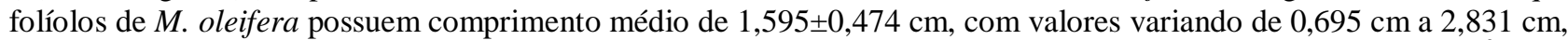
largura média dos folíolos de $1,142 \pm 0,329 \mathrm{~cm}$, variando de 0,443 a $1,950 \mathrm{~cm}$ e área média de $1,445 \pm 0,800 \mathrm{~cm}^{2}, \mathrm{com}$ valores variando entre $0,253 \mathrm{~cm}^{2}$ e $3,602 \mathrm{~cm}^{2}$. Trabalhos complementares são sugeridos para criação de modelos lineares para determinação da área dos folíolos por métodos não destrutivos.
\end{abstract}

PALAVRAS-CHAVE: Moringaceae; Medidas lineares; Área foliar.

\section{INTRODUÇÃO}

A Moringa oleifera Lamark é um membro da família de plantas Moringaceae, angiospermas perenes, que inclui 12 outras espécies. Nativa das partes sub-Himalaia do norte da Índia, é cultivada em todas as áreas tropicais e subtropicais do mundo (ROLIM et al., 2016). No Brasil, foi introduzida na década de 1950 (SILVA et al., 2013) e seu cultivo vem se expandindo no país, por ser uma espécie perene, de fácil cultivo e com múltiplas utilidades (LISITA, et al., 2018).

As folhas da $M$. oleifera estão sendo amplamente estudadas, visto que possuem grande potencial nutricional (NKAKWANA et al., 2014). Em relação à nutrição humana, as folhas desta espécie possuem elevado teor de proteínas, são ricas em aminoácidos essenciais, minerais, vitaminas e substâncias antioxidantes, constituindo-se em um alimento funcional altamente nutritivo (GOPALAKRISHNAN et al., 2016). Tem sabor agradável, podendo ser consumidas cozidas em sopas, guisados e pratos variados, sendo seu sabor ligeiramente picante. As folhas e hastes podem ser secas e usadas como condimento, polvilhando sobre os alimentos (HELVIOB, 2007).

A folha é o órgão fotossintético mais importante das plantas. Folhas participam em muitos processos fisiológicos que resultam em compensações entre fixação de carbono, perda de água, e defesa do ataque herbívoro (SHI et al., 2019). A superfície da folha apresenta-se essencialmente plana e achatada, o que facilita, consideravelmente, o aumento da relação superfície/volume, permitindo assim, a realização das trocas gasosas (ALMEIDA; ALMEIDA, 2018). Ressalta-se que a área foliar é frequentemente utilizada para medir o crescimento das plantas, estando diretamente relacionada à fotossíntese e taxa de transpiração, entre outros processos fisiológicos (TOEBE et al., 2019).

A área foliar apresenta estreita relação com a interceptação da energia solar (TRAUTENMÜLLER et al., 2017) que é imprescindível para o processo fotossintético e é muito utilizada em análises relacionadas ao acúmulo de $\mathrm{CO}_{2}$ atmosférico (LIMA et al., 2012). A estimativa da área foliar pode ser realizada através de métodos destrutivos e não destrutivos (MALAGI et al., 2011). Estes pesquisadores reportam que aqueles métodos que exigem a retirada da folha ou de outras estruturas são denominados destrutivos ou laboratoriais, sendo que as desvantagens desse método é não ser aplicável em estudos onde a quantidade de amostras é limitada.

Objetivou-se com este trabalho caracterizar morfométricamente folíolos de mudas de Moringa oleifera por método destrutivo.

\section{MATERIAL E MÉTODOS}

A pesquisa foi realizada entre os meses de outubro de 2018 e março de 2019, no Laboratório de Microbiologia do Centro de Ciências Agrárias e Ambientais (CCAA) da Universidade Estadual da Paraíba (UEPB), localizado no município de Lagoa Seca - PB, nas coordenadas de Latitude $7^{\circ} 09^{\prime} \mathrm{S}$, Longitude $35^{\circ} 52^{\prime}$ W e altitude de $634 \mathrm{~m}$ (SOARES et al., 2017). O clima local, segundo a classificação de Köppen, é do tipo As’ (tropical úmido), com temperatura média anual de $22^{\circ} \mathrm{C}$, sendo a mínima de 18 e máxima de $33^{\circ} \mathrm{C}$, precipitação pluviométrica de $800 \mathrm{~mm}$ e umidade relativa do ar de $80 \%$ (SILVA et al., 2019).

Foram utilizados 200 folíolos de $M$. oleifera coletados de mudas de seis meses de idade, cultivadas em ambiente telado com $15 \%$ de redução da luminosidade original. O cultivo foi realizado em recipientes de polietileno de $2 \mathrm{dm}^{3}$ de 
MACARIO, A. P. S. et al. Caracterização morfométrica de folíolos de Moringa oleifera por método destrutivo. In: II Congresso Paraibano de Agroecologia \& IV Exposição Tecnológica, 2019. Anais... Caderno Verde de Agroecologia e Desenvolvimento Sustentável, Pombal, v. 9, n.7, e-7025, 2019.

volume preenchidos com substrato constituído de areia e esterco bovino na proporção de 3:1. Conforme Wang et al. (2019), foram realizadas análises morfométricas para determinação do comprimento (C, mm) e largura (L, mm) dos folíolos. A largura do folíolo correspondeu a maior distância no sentido perpendicular ao comprimento do folíolo, e o comprimento foi considerado como a distância entre a base distal do pecíolo e a extremidade do terminal.

Após a realização das medidas morfométricas, os folíolos foram distribuídos em superfície contrastante de coloração branca e escaneados utilizando-se de impresso multifuncional Epson ${ }^{\circledR}$ EcoTank L375, adotando-se régua graduada em milímetros como referência de medida na imagem. As medidas de área foliar real foram realizadas utilizando-se do softwareImageJ ${ }^{\circledR}$, disponível gratuitamente via internet (http://rsbweb.nih.gov/ij/). Este software captura a imagem de todos os folíolos de uma folha completa e através de procedimentos de contraste de cores calcula a área total real (HOLGUÍN et al., 2019).

De posse dos dados da análise morfométrica e da área foliar, os folíolos foram classificados de acordo com o comprimento, a largura e a área (pequenos, médios e grandes). As classes pequeno e grande foram baseadas no primeiro e terceiro quartis da curva de distribuição de frequências de comprimento, largura e área foliar. Os folíolos cujas medidas de comprimento, largura e área eram equidistantes entre grandes e pequenos foram consideradas como médios (SOUZA et al., 2019).

Foras realizadas análises estatísticas descritivas para cálculo da média aritmética amostral, desvio padrão amostral, valor máximo e mínimo e estimativa dos intervalos de classes. Para tanto, foram utilizados os softwares Microsoft Excel v. 2016 (WINSTON, 2016) e Sisvar 5.6 (FERREIRA, 2014).

\section{RESULTADOS E DISCUSSÃO}

Com base no resumo das análises descritivas (Tabela 1), verificou-se que folíolos de M. oleifera possuem comprimento médio de $1,595 \pm 0,474 \mathrm{~cm}$, com valores variando de $0,695 \mathrm{~cm}$ a $2,831 \mathrm{~cm}$ e coeficiente de variação de 29,717 , de modo que folíolos com comprimento menor ou igual a $1,407 \mathrm{~cm}$ são considerados pequenos, maiores que $1,407 \mathrm{~cm}$ e menores ou iguais a 2,119 cm são médios e maiores que 2,119 cm são grandes.

A largura média dos folíolos foi de $1,142 \pm 0,329 \mathrm{~cm}$, variando de 0,443 a $1,950 \mathrm{~cm}$, com coeficiente de variação de 28,840, sendo considerados pequenos os folíolos menores ou iguais $0,945 \mathrm{~cm}$, médios aqueles maiores que $0,945 \mathrm{~cm}$ e menores ou iguais a $1,448 \mathrm{~cm}$ e aqueles maiores que $1,448 \mathrm{~cm}$ foram considerados grandes (Tabela 1).

Quanto à área foliar, verificou-se que os folíolos possuem área média de $1,445 \pm 0,800 \mathrm{~cm}^{2}$, com valores variando entre $0,253 \mathrm{~cm}^{2}$ e $3,602 \mathrm{~cm}^{2}$, com coeficiente de variação de 55,365, em que os folíolos com área menor ou igual a $1,369 \mathrm{~cm}$ foram classificados como pequenos, aqueles com área maior que $1,369 \mathrm{~cm}^{2}$ e menor ou igual a $2,486 \mathrm{~cm}^{2}$ foram classificados como médios e aqueles com área superior a 2,486 $\mathrm{cm}^{2}$ foram considerados grandes (Tabela 1).

Tabela 1. Resumo das análises descritivas e estimativa de classes de tamanhos a partir das dimensões lineares e área de folíolos de Moringa oleifera. Lagoa Seca, PB, 2019.

\begin{tabular}{lccc}
\hline \multirow{2}{*}{ Parâmetros } & \multicolumn{3}{c}{ Dimensões lineares de folíolos } \\
\cline { 2 - 4 } & Comprimento $(\mathrm{cm})$ & Largura $(\mathrm{cm})$ & Área foliar $\left(\mathrm{cm}^{2}\right)$ \\
\hline Média aritmética amostral & 1,595 & 1,142 & 1,445 \\
Desvio padrão amostral & 0,474 & 0,329 & 0,800 \\
Máximo & 2,831 & 1,950 & 3,602 \\
Mínimo & 0,695 & 0,443 & 0,253 \\
\hline Coeficiente de variação $(\%)$ & 29,717 & 28,840 & 55,365 \\
\hline Estimativa de classes & \multicolumn{3}{c}{ Intervalos de classes } \\
\hline Classe de folíolos pequenos & $>1,407 \leq 2,119$ & $\leq 0,945$ & $\leq 1,369$ \\
Classe de folíolos médios & $>2,119$ & $>0,945 \leq 1,448$ & $>1,369 \leq 2,486$ \\
Classe de folíolos grandes & & $>1,448$ & $>2,486$ \\
\hline
\end{tabular}

Os valores médios de comprimento e largura de folíolos encontrados nesta pesquisa foram semelhantes aos 0,9 a $1,8 \mathrm{~cm}$ de comprimento e 0,5 a $1,5 \mathrm{~cm}$ de largura relatados por Souto e Maior Júnior (2018). Nesta pesquisa, a ocorrência de folhas maiores que as relatadas por estes pesquisadores pode estar relacionada à menor disponibilidade de luz no ambiente telado com $15 \%$ de redução de luminosidade, isso porque, em condições de restrição luminosa, as plantas de pleno sol se adaptam aumentando a área e reduzindo a espessura do limbo foliar, fenômeno que comumente ocorre em função de diminuição na espessura do parênquima paliçádico e do lacunoso (ROSSATO et al., 2010; SANTOS et al., 2014).

É possível que o aumento no tamanho das folhas tenham ocorrido como uma estratégia das plantas para otimizar a captação da radiação na condição de redução de $15 \%$ da luminosidade, o que contribui para uma melhor absorção da radiação pelos tecidos do mesofilo, notadamente pelo incremento de tecidos fotossintetizantes, além de contribuir para evitação de possíveis prejuízos aos eventos metabólicos ou de desenvolvimento da planta dependentes das condições de luminosidade (PTUSHENKO et al., 2016; ARAÚJO et al., 2019).

Esta caracterização morfométrica dos folíolos de $M$. oleifera é de fundamental importância para o entendimento da dinâmica de dimensões e área, notadamente devido à importância das variáveis de comprimento e largura das folhas 
MACARIO, A. P. S. et al. Caracterização morfométrica de folíolos de Moringa oleifera por método destrutivo. In: II Congresso Paraibano de Agroecologia \& IV Exposição Tecnológica, 2019. Anais... Caderno Verde de Agroecologia e Desenvolvimento Sustentável, Pombal, v. 9, n.7, e-7025, 2019.

para estudos com espécies vegetais (CHAGAS et al., 2008), sobretudo para garantia de maior precisão na estimativa de área foliar por método não destrutivo. De fato, a contribuição desta pesquisa reside no fato de que não foram relatados na literatura limites para classificação do tamanho dos folíolos de M. oleifera. Souza et al. (2019), trabalhando com sementes crioulas de feijão, estimaram classes de tamanhos de sementes e reportaram que estas informações são imprescindíveis para seleção de sementes para cultivo.

\section{CONCLUSÕES}

Folíolos de $M$. oleifera possuem comprimento médio de $1,595 \pm 0,474 \mathrm{~cm}$, com valores variando de $0,695 \mathrm{~cm}$ a $2,831 \mathrm{~cm}$, largura média dos folíolos foi de $1,142 \pm 0,329 \mathrm{~cm}$, variando de 0,443 a 1,950 cm e área média de $1,445 \pm 0,800$ $\mathrm{cm}^{2}$, com valores variando entre $0,253 \mathrm{~cm}^{2}$ e $3,602 \mathrm{~cm}^{2}$. Trabalhos complementares são sugeridos para criação de modelos lineares para determinação da área dos folíolos por métodos não destrutivos.

\section{REFERÊNCIAS}

ALMEIDA, M. de; ALMEIDA, C. V. de. Morfologia da folha de plantas com sementes. Piracicaba: ESALQ/USP, 2018. 111 p. (Coleção Botânica, 3).

ARAÚJO, L. L. N.; MELO, H. C. de; CASTIGLIONI, G. L.; GONÇALVES, L. A. Intensidade de radiação influenciando características morfofisiológicas em folhas de Tetradenia riparia (Hochst.) Codd. Iheringia, Série Botânica, Porto Alegre, v.74, e2019001, 2019.

CHAGAS, M. das G. S. das; SILVA, M. D. da; GALVÍNCIO, J. D.; PIMENTEL, R. M. de M. Variações foliares em grupos funcionais vegetais de uma paisagem de restinga, Pernambuco-Brasil. Revista Brasileira de Geografia Física, Recife, v.1, n.2, p.50-63, 2008.

FERREIRA, D. F. Sisvar: a Guide for its Bootstrap procedures in multiple comparisons. Ciência e Agrotecnologia, Lavras, v.38, n.2, p.109-112, 2014.

GOPALAKRISHNAN, L.; DORIYA, K.; KUMAR, D. S. Moringa oleifera: A review on nutritive importance and its medicinal application. Food Science and Human Wellness, v.5, n.2, p.49-56. 2016.

HELVIOBH (2007). Moringa oleifera, el maná verde del trópico, cultivo, comercialización. Disponível em: <http://helviobh.googlepages.com/ morigaoleifera>.

HOLGUÍN, V. A.; GRISALES, S. O.; DÍAZ, G.; MORA-DELGADO, J. Estimation of leaf area of Tithonia diversifolia using allometric equations. Tropical And Subtropical Agroecosystems, v.22, p.231-238, 2019.

LIMA, R. T.; SOUZA, P. J. O. P.; RODRIGUES, J. C.; LIMA, M. J. A. Modelos para a estimativa da área foliar da mangueira utilizando medidas lineares. Revista Brasileira de Fruticultura, Jaboticabal, v.34, n.4, p.974-980, 2012.

LISITA, F. O.; JULIANO, R. S.; MOREIRA, J. S. Cultivo e Processamento da Moringa na alimentação de Bovinos e Aves. Circular Técnica 119. Corumbá, 2018.

MALAGI, G.; CITADIN, I.; SCARIOT, S.; REIS, L. Método não destrutivo para determinação da área foliar da videira, cultivar BRS-Violeta. Revista Brasileira de Fruticultura, Jaboticabal, v.32, n.4, p.1250-1254, 2011.

NKAKWANA, T. T.; MUCHENJE, V.; PIETERSE, E.; MASIKA, P. J.; MABUSELA, T. P.; HOFFMAN, L. C.; DZAMA, K. Effect on Moringa oleifera leaf meal on growth performance, apparent digestibility, digestive organ size and carcass yield in broiler chickens. Livestock Science, Suwon, v.161, p.139-146, 2014.

PTUSHENKO, V. V.; PTUSHENKO, O. S., SAMOILOVA, O. P.; SOlOVCHENKO, A. E. An exceptional irradiance-induced decrease of light trapping in two Tradescantia species: an unexpected relationship with the leaf architecture and zeaxanthin-mediated photoprotection. Biologia Plantarum, Praha, v.60, p.385-393, 2016.

ROLIM, J. C.; NOGUEIRA, R. S.; LIMA, P. R. S.; PORDEUS, M. A. A; CASTRO, A. A.; PITTA, G. B.; DINIZ, M. F. F. M.; PEREIRA, A. H. Hiperplasia miointimal na artéria ilíaca em coelhos submetidos à angioplastia e tratados com Moringa oleifera. Revista do Colégio Brasileiro de Cirurgiões, Rio de Janeiro, v.43, n.1, p.028-034, 2016. 
MACARIO, A. P. S. et al. Caracterização morfométrica de folíolos de Moringa oleifera por método destrutivo. In: II Congresso Paraibano de Agroecologia \& IV Exposição Tecnológica, 2019. Anais... Caderno Verde de Agroecologia e Desenvolvimento Sustentável, Pombal, v. 9, n.7, e-7025, 2019.

ROSSATO, D. R.; TAKAHASHI, F. S. C.; SILVA, L. C. R.; FRANCO, A. C. Características funcionais de folhas de sol e sombra de espécies arbóreas de uma mata de galeria no Distrito Federal, Brasil. Acta Botanica Brasilica, Porto Alegre, v.24, p.640-647, 2010.

SANTOS, M. S.; FEIJÓ, N. S. A.; SECCO, T. M.; MIELKE, M. S.; GOMES, F. P.; COSTA, L. C. B.; SILVA, D. C. 2014. Efeitos do sombreamento na anatomia foliar de Gallesia integrifolia (Spreng) Harms e Schinnus terebinthifolius Raddi. Revista Brasileira de Plantas Medicinais, Botucatu, v.16, p.89-96, 2014.

SHI, P.; LIU, M.; YU, X.; GIELIS, J.; RATKOWSKY, D. A. Proportional relationship between leaf area and the product of leaf length and width of four types of special leaf shapes. Forests, Dordrecht, v.10, n.2, p.178, 2019.

SILVA, A. E.; FERRAZ, R. L. de S.; SILVA, J. P. da; COSTA, P. da S.; VIEGAS, P. R. A.; BRITO NETO, J. F. de; MELO, A. S. de; MEIRA, K. S.; SOARES, C. S.; MAGALHÃES, I. D.; MEDEIROS, A. de S. Microclimate changes, photomorphogenesis, and water consumption by Moringa oleifera cuttings under light spectrum variations and exogenous phytohormones concentrations. Australian Journal Of Crop Science, 2019. In Press.

SIlVA, T. C. S.; NUNES, T. P.; COSTA, D. G.; LIMA, L. A. L. C.; SILVA, G. F.; OLIVEIRA JUNIOR, A. M. Utilização de sementes de Moringa oleifera como alternativa para produção de biodiesel. Revista Genitec: Gestão, Inovação e Tecnologias, v.3, n.2, p.12-25, 2013.

SOARES, C. S.; SILVA, J. A.; SILVA, G. N. Produção de coentro em diferentes espaçamentos dos canais hidropônicos. Pesquisa Agropecuária Pernambucana, Recife, v.22, p.1-5, 2017.

SOUTO, P. C.; MAIOR JÚNIOR, S. G. S. Origem, botânica e morfologia da Moringa. In: SILVA, G. F.; SANTANA, M. F. S.; LIMA, A. K. V. O.; BERGAMASCO, R.; PAIVA, P. M. G.; SANT'ANNA, M. C. S.; SERAFINI, M. R.; BERY, C. C. S. (eds.). Potencialidades da Moringa oleifera Lam. São Cristóvão: Universidade Federal de Sergipe, 2018. cap.1, p.15-36.

SOUZA, L. F.; ARAÚJO, M. S.; FERRAZ, R. L. S.; COSTA, P. S.; MEDEIROS, A. S.; MAGALHÃES, I. D. Sementes crioulas de feijão comum (Phaseolus vulgaris L.) para cultivo agroecológico. Revista Verde de Agroecologia e Desenvolvimento Sustentável, Pombal, v.14, n.1, p.33-40, 2019.

TOEBE, M.; SOUZA, R. R.; MELlO,' A. C.; MELO, P. J.; SEGATTO, A.; CASTANHA, A. C. Leaf área estimation of squash 'Brasileirinha' by leaf dimensions. Ciência Rural, Santa Maria, v.49, n.4, p.1-11, 2019.

TRAUTENMÜlleR, J. W.; BORElla, J.; MiNATTI, M.; COSTA JÚNIOR, S.; WOYCIKIEVICZ, A. P. F.; BALBINOT, R.; ENGEL, K. Crescimento de área foliar e índice de área foliar de mudas de Cordia americana em diferentes formas de manejo. BIOFIX Scientific Journal, v.2, n.2, p.60-64, 2017.

WANG, Y.; JIN, G.; SHI, B.; LIU, Z. Empirical models for measuring the leaf area and leaf mass across growing periods in broadleaf species with two life histories. Ecological Indicators, v.102, p.289-301, 2019.

WINSTON, W. Microsoft Excel data analysis and business modeling. 5. ed. Microsoft press, 2016.

\section{AGRADECIMENTOS}

Apoio financeiro: Fundação de Apoio à Pesquisa do Estado da Paraíba - FAPESQ. 